\title{
YOUTH AND MENTAL HEALTH: LIFE SATISFACTION, WELLBEING, AND SOCIETAL PARTICIPATION IN THE CONTEXT OF A TRANSITIONING STATE
}

DOI: 10.36740/WLek202107123

\author{
Viktor V. Vus', Elena V. Syurina' ${ }^{2}$, Tanya Brückner², Evangelos C. Fradelos ${ }^{3}$, Ioanna V. Papathanasioư ${ }^{3}$, \\ Liudmyla M. Omelchenko ${ }^{4}$, Tetyana M.Vakulich ${ }^{5}$ \\ 'NATIONAL ACADEMY OF EDUCATIONAL SCIENCE, KYIV, UKRAINE \\ 2VRIJE UNIVERSITY, AMSTERDAM, NETHERLANDS \\ 3UNIVERSITY OF THESSALLY, VOLOS, GREECE \\ ${ }^{4}$ NATIONAL UNIVERSITY OF LIFE AND ENVIRONMENTAL SCIENCE, KYIV, UKRAINE \\ 5INDEPENDENT RESEARCHER, KYIV, UKRAINE
}

\begin{abstract}
The aim: Youth are important societal actors. This is especially relevant when considering countries in transition such as Ukraine. This study examines well-being and societal participation - both key signifiers of mental health - of youth in Ukraine.

Materials and methods: A descriptive, cross-sectional survey with open and closed questions was utilized $(n=1562)$. Participants were asked to reflect on social concerns and to evaluate their well-being in different life spheres and their own mental health through activities such as interpersonal communication, self-perception and relaxation.

Results: Students showed positive mental health through their daily activities, but mental health indicated by life satisfaction ranged according to activities, age, gender and environment. Willingness to volunteer and connection to life can be attributed to feelings of learned helplessness in the face of problems deemed too complex, and participation in volunteering was linked to positive mental health and feelings of empowerment.

Conclusions: The study contributes to understanding the status of Ukrainian youth's mental health and the ways in which mental health is expressed. The results of the research assist in identifying avenues to reduce the impact of social frustration, improve mental health of citizens of transitional countries, and encourage social stability.
\end{abstract}

KEY WORDS: youth, Mental Health, well being, lifesatisfaction, societal participation

Wiad Lek. 2021;74(7):1687-1694

\section{INTRODUCTION}

Despite substantial advances in research about ways in which to both promote mental health and to prevent and treat mental disorders, the global burden of disease due to mental disorders has continued to rise across all countries [1]. This has particular relevance for youth in transitioning states: countries transitioning from past socioeconomic and political structures towards new ones [2]. Youth have the ability to impact the social, cultural and economic development of a country, but they are considered particularly vulnerable to social and contextual factors $[1,3,4]$. Therefore, acting early to promote youth mental health and prevent and treat mental ill health provides an avenue to combat stigma surrounding mental health, promote help-seeking behaviour, and reduce disparities in mental health [1]. It can also have a positive impact on the reduction of youth criminal behaviour, use of welfare benefits, and future unemployment [5] Further benefits of prompt action include savings from improved health outcomes, improved academic performance, improved social and emotional functioning, amelioration of the effects of social and economic disadvantage, and increased resilience [3].

\section{MENTAL HEALTH AND TRANSITIONAL EXPERIENCES}

The global rise in mental health disorders and diagnoses can largely be attributed to major transitions across environmental, socio-political and demographic contexts [1]. Factors known to lead to mental health disorders, such as abuse, neglect and social exclusion, are also prevalent in transitioning countries and may be adversely impacted during transitions. Government investment in mental health remains inadequate in these countries, but they are not unique in this respect. Physical health services continue to have priority over mental health services, which often receive less than ten percent of overall health 
funding $[6,7]$. All of the above lead to inadequate mental health service quality, and an overall failure to respond to the global mental health crisis [1]. It is therefore especially interesting to review the state of mental well-being in countries undergoing transition.

Central and Eastern Europe (CEE), in which Ukraine is included, is commonly acknowledged as a transitional region [8]. Twenty-eight countries have arisen out of former communist countries under the Soviet Union's rule, which means countries in CEE are in transition towards (re)defining their cultural, social, political and economic systems as they attempt to distance themselves from the concept of 'Eastern Europe' and their communist past [8]. Many such countries are faced with 'rebranding' as they attempt to construct new national identities that are also linked to their citizens' personal identities. Consequently, discussion about identity issues is prevalent in countries such as Ukraine. Identities are intrinsically linked to interpretations of reality and experiences, and predicated on common constructions of meaning through interpersonal relations and shared experiences [8].

Challenges facing countries in transition include social, cultural and economic factors. One major transition experienced in the CEE was that from a communist labour market and economy to that of a more western, capitalist labour market during a global recession [9]. This change impacted development and stability of job markets, especially in the middle-class sector, and coincided with a widening gap between income and living costs, as well as rising youth unemployment [9]. Additionally, the structure of work, education, family and housing life-stage transitions changed, all of which are crucial in forming young people's expectations and experiences. Youth have had to redefine the transitional phase of emerging adulthood, as well as their political inclinations and the way in which they want to lead their lives [9]. However, youth across the globe are also experiencing changes in life courses, increased self-awareness, and increased emphasis on individualisation due to a number of reasons, such as globalization $[1,9]$. Therefore, while youth in transitional countries like Ukraine experience unique challenges as a result of their history, one can also apply global understandings of challenges facing young people and their mental health to such a context.

Consequently, it is important to examine mental well-being and societal participation of youth in a transitioning state like Ukraine. Up until now this area has been neglected in international research, with studies focusing either on children and adolescents [10], specific groups of vulnerable youth [11], or specific problematic behaviours and disorders $[12,13]$.

\section{THE AIM}

Youth are important societal actors. This is especially relevant when considering countries in transition such as Ukraine. This study examines well-being and societal participation - both key signifiers of mental health - of youth in Ukraine.

\section{MATERIALS AND METHODS}

\section{SETTINGS}

In this study, a descriptive, cross-sectional research design was utilized. The study sample consisted of 1,564 students (18-22 years old), who were randomly selected from seven higher educational institutions (HEIs) in the North and Central regions of Ukraine. This geographical diversification, alongside the number of students, allowed the representation of a population of 10,000 youth in a modern country in transition (Ukraine).

A mixed-methods design was used. The data were collected in a three-part survey conducted between 11 March and 10 April 2018. The survey design collected data on: (a) demographics as well as social and work characteristics of respondents; (b) study respondents' reflection on social conditions; and (c) respondents' reflections on and representation of their daily life and activities (as a proxy for mental health states).

\section{DATA COLLECTION TOOLS}

The first part of the survey collected socio-demographic information through 14 standard questions on age, gender, living situation, employment status and affinity (if any) with mental health services.

In the second part of the survey, participants responded to a set of open-ended questions asking them to reflect on social concerns (perception of global, regional and local social challenges; conditions and motivation for conducting volunteer work; social representation activities). Next, they were asked to evaluate their well-being in different life spheres (pragmatic-material, social, civil, intellectual, ethic, aesthetic; spiritual-transcendental) by rating these on a Likert scale of 1-10 (where 10 is best) and to indicate whether these were performed out of enjoyment or out of duty (mechanical).

The third survey section asked respondents to reflect on their own mental health, and included a set of 32 questions. Mental health was conceptualised as a combination and interaction of a range of activities. This was inspired by the recommendations of the Mental Health Foundation in the UK. Among the areas researched were: interpersonal communication, physical activity, eating and drinking, listening to one's own body, social representation, mental and physical relaxation, self-perception and interpersonal relationships. For each question, respondents were asked to identify the average amount of time spent on the specific activity (in minutes per week), and to define in their answers whether the activities were carried out as part of an enjoyable pursuit or whether they were of more routine nature.

\section{DATA ANALYSIS}

The survey results consisted of both qualitative and quantitative data. For analysis of the qualitative data, content analysis was performed using manual thematic coding approach. 
Quantitative analysis was performed using SPSS version 24 (Armonk, NY: IBM). Due to the fact that data collected was a mix of categorical and nominal data, aside from the descriptive statistics, Pearson's Chi-Square analysis was used. For this analysis, p-values were two-tailed, and a p-value $\propto \leq 0.05$ was considered as statistically significant. This analysis helped to pinpoint the specificity of associations between socio-demographic characteristics and conceptualisation of societal problems, and the level of self-reflection on and representation of the young generation's mental health. Volunteering was analysed as reflective of societal participation.

\section{RESULTS}

Upon presentation of the demographic characteristics of the participants, their visions of the main current social problems will be presented, followed by analysis of their societally relevant leisure activities, namely volunteering activities. Next, we present the findings regarding the general life satisfaction of the students, and finally some statistics are provided regarding mental health and selfcare related activities: general reflection on one's own mental well-being, physical exercise, mental relaxation, and help-seeking behaviour.

\section{DEMOGRAPHIC CHARACTERISTICS}

The sample consisted of 1564 higher education students living in the Northern and Central regions of Ukraine. The sample was predominantly female ( $77.7 \%$ female). The students' ages ranged between 18 and 21, with a mean of 19.33 ( $\mathrm{SD}=0.94)$. The majority of participants lived in urban areas (77.7\%). This, however, can be explained by the fact that the vast majority of higher education institutions in Ukraine are situated in urban areas. Regarding their housing situations, none of the respondents lived alone: $78 \%$ lived in university dorms, $27.6 \%$ reported living with friends or family, and $5.63 \%$ stated that their living situation was unstable. Due to the fact that participants could select multiple answer models, percentages reported do not add up to $100 \%$. For example, some students live in dorms during term time but live with family or friends outside of the university calendar. Only $11 \%$ of the respondents reported having a paid job: $5.5 \%$ had full-time employment and $5.5 \%$ had part-time employment. None of the students reported any relationship to mental health services.

\section{REFLECTION ON SOCIAL PROBLEMS}

The participants were able to list up to five main social problems on three levels: global, regional and local. According to the results of semantic analysis, the young generation identified the following social problems: poverty, low quality of social support, low quality of health protection, gender discrimination, children growing up without parents, low quality of education and professional development, ecological problems, criminal activity and corruption, unemployment, social instability, lack of common values, lack of leading ideology, reduction in the value of human life, overpopulation, migratory processes, digitalization and robotization of human life. The number of problems listed for each of the levels can be seen as demonstrating the degree of concern with different levels of societal issues. Most problems (reduction in the value of human life, overpopulation, migratory processes, digitalization and robotization of human life) were listed on the global level $(M=2,2164, S D=1,22823,95 \%$ CI: 2,$1554 ; 2,2773$ ), followed by social issues at the regional level (gender discrimination, ecological problems, criminal activity and corruption, unemployment, social instability, lack of common values, lack of leading ideology) $(\mathrm{M}=1,9968$, $\mathrm{SD}=1,24998$, 95\% CI: 1,$9348 ; 2,0588$ ). The least number of issues were named on the local level (poverty, low quality of social support, low quality of health protection, children growing up without parents, low quality of education and professional development) ( $\mathrm{M}=1,6095, \mathrm{SD}=1,06357,95 \%$ CI: 1,$5567 ; 1,6623)$. The difference between the means was statistically significant.

\section{VOLUNTEERING ACTIVITY}

Volunteering was shown to be a purely female activity, with none of the male participants reporting any volunteering. The participation rate among solely 19 -year-old females was $28.6 \%$. It is important that across all the age groups, only the group of 19-year-olds reported volunteering activities. Within this age group, $55.5 \%$ of females reported participating in volunteering activities.

Volunteering was reported only by the urban population: $28.6 \%$ of all urban participants reported volunteering. The most common spheres for volunteering can be found in Table I. In order to be actively involved in building civil society and social reformation, the respondents said they would prefer to conduct their volunteer activity in "social and art projects" (72\%), "support of events" (54\%) or "work with disabled people and children" (28\%). However, 38\% of respondents reported no involvement in volunteer activities, and $32 \%$ of respondents reported no motivation to do volunteer work, or to work without a salary.

When answering the question about their potential interest/wish for volunteering, none of the males reported a wish to volunteer, compared to $64.7 \%$ of females. There was no significant difference between rural and urban groups regarding the wish to engage in volunteering activities. However, rural participants reported that they wished to spend significantly less time volunteering compared to their urban counterparts. Details on the reported wish to volunteer can be found in Table II.

The wish to volunteer was predicted by the number of social issues mentioned on the three levels (global, regional and local). A multiple regression was calculated to predict the wish to volunteer based on the number of global, regional and local problems reported. A significant regression equation was found $(F(3,1558)=127.729, p<.000)$, with an R2 of 197 . Participants' predicted wish to volunteer is equal to $832.133+$ $(-227.754)$ global issues $+(-52.183)$ regional issues + 
Table I. Volunteering activities among 19-year-olds

\begin{tabular}{ccc}
\hline \multirow{3}{*}{ Spheres of activities } & Fitness and physical activities & $54 \%$ \\
\cline { 2 - 3 } & Child development programs & $50 \%$ \\
\cline { 2 - 3 } Motivation for volunteering & Educational programs & $34 \%$ \\
\hline & To gain moral satisfaction & $62 \%$ \\
\hline
\end{tabular}

Table II. Wish to volunteer

\begin{tabular}{ccc}
\hline $\begin{array}{c}\text { Wish to } \\
\text { volunteer by } \\
\text { gender }\end{array}$ & Males & $0 \%$ \\
\cline { 2 - 3 } & Females & $64.70 \%$ \\
\hline \multirow{2}{*}{$\begin{array}{c}\text { Wish to } \\
\text { volunteer by age }\end{array}$} & 18-year old & $66.90 \%$ \\
\cline { 2 - 3 } & 20-year old & $55.80 \%$ \\
\hline & 21-year old & $06.28 \%$ \\
\hline $\begin{array}{c}\text { Wish to } \\
\text { volunteer by } \\
\text { place of living }\end{array}$ & Urban & $50.12 \%$ \\
\cline { 2 - 3 } & Rural & $49.86 \%$ \\
\hline
\end{tabular}

71.266 local issues. Willingness to volunteer reduced by 227.754 and 52.183 minutes per week respectively for each additional social problem named at the global and regional levels respectively. However, willingness to volunteer was positively influenced by the number of local issues seen by the respondents. Each additional issue seen on a local level increased the willingness to volunteer by 71.266 minutes.

\section{LIFE SATISFACTION}

Within the sub-set of questions about life satisfaction, participants were asked to rate their satisfaction on a 10 point Likert scale with: their material well-being, level of social involvement, engagement with civil society, opportunities to engage in meaningful intellectual interactions with others, living according to common moral societal values, satisfaction with comforts of their daily life, and having the ability to engage and express oneself spiritually. These represent material, social, political, intellectual, ethical, aesthetic and religious aspects of life.

Mean satisfaction was the lowest for ability to engage and express yourself spiritually $(\mathrm{M}=3.0, \mathrm{SD}=1.84)$ and engagement with civil society $(M=3.9, S D=1.37)$. The highest rates of satisfaction were reported for beauty and comforts of life $(\mathrm{M}=7.6, \mathrm{SD}=1.28)$ and opportunities to intellectually interact with others $(\mathrm{M}=7.29, \mathrm{SD}=2.33)$.

There was a significant difference between mean levels of satisfaction with all aspects researched and age of the respondents. 18-year-old respondents showed significantly higher levels of satisfaction with all aspects compared to older age groups studied.

For most problems (except engagement in civil society and satisfaction with beauty and comforts of own life) there was a significant difference $(\mathrm{p}<.005)$ in satisfaction rate between males and females. For satisfaction with material well-being and social involvement, males had significantly higher rates of satisfaction. Females reported higher satisfaction rates for opportunities for intellectual interaction with others, living according to moral and public values, and ability to engage and express oneself spiritually. For all above, $\mathrm{p}<.005$.

Significant differences were found in the mean life satisfaction between urban and rural populations (except for engagement in civil society and satisfaction with beauty and comforts of own life). Rural youth reported significantly higher satisfaction rates for material well-being and ability to engage and express oneself spiritually. Urban youth reported higher levels of satisfaction with level of social involvement, opportunities for intellectual interaction with others, and living according to moral and public values. For all above, $\mathrm{p}<.001$.

\section{DAILY ACTIVITIES}

Among the factors measured as a proxy of mental health state were: performing daily physical chores (housework, groceries), exercising (gym and sports), drinking alcohol, drinking coffee, mental and physical relaxation, self-education, and assisting friends and family. Participants were asked to report hours per week that they spend on these activities and whether these were pleasurable for them (enjoyment) or were performed out of duty (mechanical). See Table III for descriptive statistics.

On average, the students enjoyed their daily activities, as the only category where more hours were spent on mechanical performance was self-education. As seen by these findings, most of the students' time is spent on daily physical chores and self-education. A significant number of hours per week were reported to be spent on relaxation (>1500 minutes, or 25 hours a week)

\section{DISCUSSION}

This paper presented an initial investigation of the mental well-being and societal participation of higher education students from Central and Northern Ukraine.

\section{WELL-BEING AND LIFE SATISFACTION}

Students were least satisfied with their possibilities to for spiritual self-expression and highest for comforts of daily 
Table III. Factors of mental health state

\begin{tabular}{|c|c|c|c|c|c|c|}
\hline & & $\mathbf{N}$ & Minimum & Maximum & Mean & $\begin{array}{c}\text { Std. } \\
\text { Deviation }\end{array}$ \\
\hline \multirow{2}{*}{ Daily physical chores } & Enjoyment & 1562 & 0,00 & 2300,00 & 720,3841 & 682,66622 \\
\hline & Mechanical & 1562 & 0,00 & 1800,00 & 360,0896 & 500,73130 \\
\hline \multirow{2}{*}{ Exercising } & Enjoyment & 1562 & 0,00 & 600,00 & 167,4840 & 185,90501 \\
\hline & Mechanical & 1562 & 0,00 & 300,00 & 59,0877 & 84,98398 \\
\hline Drinking alcohol & & 1562 & 0,00 & 180,00 & 14,4494 & 42,24616 \\
\hline \multirow{2}{*}{ Drinking coffee } & Enjoyment & 1562 & 45,00 & 350,00 & 180,5506 & 97,19489 \\
\hline & Mechanical & 1562 & 0,00 & 240,00 & 31,1044 & 66,15950 \\
\hline \multirow{2}{*}{ Mental and physical relaxation } & Enjoyment & 1476 & 0,00 & 1500,00 & 307,8930 & 391,99511 \\
\hline & Mechanical & 1476 & 0,00 & 105,00 & 16,1348 & 32,03943 \\
\hline \multirow{2}{*}{ Self-education } & Enjoyment & 1475 & 1,00 & 1000,00 & 438,6556 & 345,41380 \\
\hline & Mechanical & 1475 & 0,00 & 1260,00 & 203,9322 & 321,59266 \\
\hline \multirow{2}{*}{ Helping friends and family } & Enjoyment & 1390 & 0,00 & 900,00 & 229,7410 & 241,29317 \\
\hline & Mechanical & 1390 & 0,00 & 420,00 & 103,5036 & 135,40393 \\
\hline
\end{tabular}

life and intellectual interact interaction. Life satisfaction was used as a measure of mental well-being, as the more satisfied one is with one's life, the better mental well-being one has. As with volunteering activities, younger people had a higher level of satisfaction, with the highest levels observed among 18-year-olds.

Participants indicated enjoying their daily activities - a proxy measure of mental health - suggesting a generally good level of mental health. Daily chores occupied the highest proportion of the young people's time. However, they also expressed a high level of satisfaction with these activities. The second largest proportion was self-education, but this differed from other activities, as most hours were not experienced as pleasurable for the participants. This could be because of a misinterpretation of the question - it is possible the students did not see the difference between formal education and self-education. Daily chores and self-education were used as measures of mental well-being, as if one is able to spend time performing daily chores and self-education, one is more likely to have better mental health than if one spends very little time on such activities $[14,15,16]$.

Survey responses received from young adults in Ukraine evidence a high or good degree of satisfaction with their home lives, but also a degree of disconnection from local community life and concerns about the impact of global issues over which they could expect to exert little control, which has been identified as an issue among youth globally. In an atmosphere of societal and economic transition, the feeling of being subject to forces outside of one's control can have a mental health impact [5]. One result could be focusing on personal and family connections, which is hardly negative. However, it can impact on how society transitions if youth do not feel as if they can make a positive difference in their nation, as well as if they feel less hopeful and ineffective.

\section{VOLUNTEERING AND SOCIAL PARTICIPATION}

Volunteering was used as a measure of social participation in this study, and linked to social well-being, as some research suggests volunteering should be promoted as a type of 'healthy lifestyle' by public practitioners, public health, and education, especially for people who experience poorer health and societal disadvantages [17]. Other studies have found that long-term engagement in volunteering has proven to positively impact mental health, as it promotes higher levels of psychological well-being, such as self-acceptance, and feelings of competence, growth and engagement [18].

Youth mental health needs to be understood in the broader perspective of global phenomena and within the intersection of global and local contexts [19]. In this study, participants were much more aware of and focused on global social issues, such as the reduction in value of human life, overpopulation, migratory processes, digitalization and robotization of human life, than on regional and local issues. This focus on global problems can add a mental health vulnerability, as it can leave youth feeling powerless and vulnerable to forces outside their control $[20,21]$. This concept can be linked to the theory of locus of control, the degree of control people believe they have over their lives (internal control) as opposed to the extent of control by external forces (external control) [8] Learned helplessness can develop when people experience perceived or real absence of control over the outcomes of difficult situation or problems, reducing their inclination to engage in problem-solving activities. Learned helplessness can be linked to experiencing depression and/or anxiety [5].

A number of studies have been published on the cultural and historical barriers to volunteering in the Eastern European region, which include the impact of communist state requirements to volunteer for a common cause [20]. 
In this study, participants' awareness of and focus on global social issues affected their willingness to participate in volunteering on the local level. This study found that in Ukraine, volunteering is a way to move away from learned helplessness and towards feeling empowered to have an impact and 'make a difference.' The more comfortable participants were with their own mental health, the more likely they were to volunteer. This echoes the findings of Thoits \& Hewitt (2001), who found that well-being and volunteering reciprocally and positively influence each other [22].

The findings of this study can therefore be used to enhance health literacy campaigns regarding mental well-being and general health. Other recommendations from literature include youth advisory boards, youth-specific marketing, design of services that focus on prevention of youth-specific problems that can lead to serious disorders, as well as youth-friendly treatment for major mental health disorders $[23,24,25]$.

\section{CONSTRUCTIVISM AND CONTEXT}

While socio-environmental contexts can impact individual wellbeing, the lines of influence can be reversed. This has special resonance for youth in transitional states. According to the concept of constructivism, people play an active role in the construction of reality and knowledge, often through interaction with others [26]. Human development is theorized to be socially situated, as people construct their experiences and identities through socio-cultural awareness [26].

Shared functional meaning can arise when people interact and discuss their ideas and interpretations of reality [27]. Similarly, the manner in which people interact with the social environment can inform their constructions of meaning. The social and relational environment can therefore have a significant impact on one's mental health and wellbeing, indicating that in a transitioning society, youth and other societal groups are actively involved in common constructions of meaning

Social suffering [28] refers to the impact of a social environment on people, as well as how this impact on a person can influence responses to social issues. The concept acknowledges the difficulty of categorising 'human problems' such as substance abuse and depression as individual problems that are purely medical or psychological in nature - in other words, the difficulty of separating such issues from contextual and societal factors (ibid.). Due to the relationship between societal problems and personal issues, these authors suggest that suffering can be not only an individual experience, but also a social and collective experience. Norms and societal practices, alongside cultural and political factors, lead to cultural experiences and representations of social suffering. In the context of Ukraine, transition processes can mediate against recognition of the collective nature of societal problems, encouraging attribution to individuals, and can also reduce impetus for collective solutions. Individ- ual attribution also reduces feelings of self-efficacy and empowerment.

\section{LIMITATIONS}

This study presents results of a cross-sectional survey run in a cohort of higher education students in Ukraine. Despite the large sample size, the sample cannot be seen as representative of all youth in Ukraine, as it is a sub-sample of highly educated youth. Additionally, the student samples are from the North and Central regions of Ukraine, which are more politically and socially stable than other regions.

The survey was not previously validated, as it was constructed specifically for this study. However, due to the descriptive and investigative nature of this study, the survey provided a good link between the scoping research question at hand, and a survey form that would not be burdensome for participants.

\section{CONCLUSIONS}

This mixed-methods study about youth mental health in Ukraine, a country in transition, contributes to understanding the status of Ukrainian youth's mental health and the methods they use to express it, such as societal participation through volunteering. Our findings show that on average, participants enjoyed their daily activities, which points to positive mental health status. Life satisfaction, also indicative of mental health, ranged according to activities, age, gender and environment. The most significant finding in life satisfaction was that participants felt least satisfied with opportunities to express themselves spiritually and most satisfied in the ability to interact intellectually and in the comfort of daily life. Participants reported feeling most concerned with global problems, such as overpopulation and the reduction in the value of human life, while they reported the least concern about local problems, such as low quality of social support and low quality of education. The level of concern with social problems corresponded with willingness to volunteer, where participants were most likely to volunteer to address local problems, and least likely with regards to global problems. Participants also indicated high satisfaction with their home lives, but disconnection from community life and issues considered outside of their control, such as global issues. The willingness to volunteer, as well as feelings of connectedness to life, could be attributed to feelings of learned helplessness in the face of complex global problems and, for those who gave issues closer to home more attention, feeling empowered to address problems whose solutions seemed more attainable, such as local issues. Therefore, participation in volunteering could be used to increase feelings of self-efficacy and empowerment among youth, with positive mental health impacts.

In summary, the results of this investigation suggest avenues to reduce the impact of social frustration, improve the mental health of citizens of transitional countries, and encourage social stability. 


\section{RECOMMENDATIONS}

Recognition of the mental health benefits of volunteering suggests that additional societal support for this activity is needed. This could include information support (creation of information platforms, social advertising) as well as material support (arranging accessible areas for communication, creativity, physical education) for the formation and development of new forms of volunteering aimed at ensuring the need for live interpersonal communication, self-development (including professional development), in support for physical health, especially in urban environments. This approach would assist youth to find meaningful connection to the civil society in which they are developing. It is also vital to promote the civic engagement of young people, including through links with local charities and international volunteer organizations.

Based on the present findings, we suggest expending the study, and increasing its mental health and well-being components. This could include introducing a more structured quality of life sub-section and a simple mental health inventory. This needs to be done carefully, however, as high levels of stigma and misconceptions about mental health in Ukraine may lead respondents to give socially desirable responses.

\section{REFERENCES}

1. Patel V., Shekhar S., Lund C. et al. The Lancet Commission on global mental health and sustainable development. Lancet. 2018;392(10157): 1553-1598. doi: 10.1016/50140-6736(18)31612-X.

2. Szoni $G$. The role and challenges of country branding in transition countries: The Central and Eastern European experience. Place Branding and Public Diplomacy. 2007; 3(1): 8-20. doi: 10.1057/palgrave. pb.6000044.

3. Patton G., Sawyer S., Santelli J. et al. Our future: A Lancet commission on adolescent health and wellbeing. Lancet. 2016; 11; 387(10036): 2423-2478. doi: 10.1016/50140-6736(16)00579-1.

4. Sweeting H., West P., Young R., Der G. Can we explain increases in young people's psychological distress over time? Soc Sci Med. 2010; 71(10): 1819-1830. doi:10.1016/j.socscimed.2010.08.012.

5. Chunling L., Zhihui L., Patel V. Global child and adolescent mental health: The orphan of development assistance for health. PLoS Med. 2018; 15(3). doi: 10.1371/journal.pmed.1002524.

6. World Health Organisation. (2018a, March 30). Mental Health: Strengthening our Response. Retrieved from: https://www.who.int/ news-room/fact-sheets/detail/mental-health-strengthening-ourresponse.

7. World Health Organisation. Mental health: Massive scale-up of resources needed if global targets are to be met. 2018. https://www.who.int/ mental_health/evidence/atlas/atlas_2017_web_note/en/.

8. Rotter J. Social Learning and Clinical Psychology. Prentice-Hall: Englewood Cliffs, NJ. 1954.

9. Roberts K. Youth in Transition: In Eastern Europe and the West. Hampshire: Palgrave Macmillan. 2009.

10. Pavlova I. Life quality and health of children and youth of Ukraine. Slobozhanskyi Herald of Science and Sport. 2015; 2(46), 131-136.

11. Busen N., Engebretson J. Facilitating risk reduction among homeless and street-involved youth. J Am Assoc Nurse Pract. 2008; 20(11): 567-575.
12. Herasym H., Herus 0., Klymanska L., Savka V., Sieroslawski J.The problem of alcohol consumption in Lviv in the sociological dimension (by the materials of the empirical research). Mental Health: Global Challenges Journal. 2019: 28-35. doi: 10.32437/MHGCJ-2019(0).66.

13. Kolisnyk L., Čekrlija Đ., Kalagurka B. Peculiarities of superiority and inferiority complexes of Ukrainians. Mental Health: Global Challenges Journal. 2020; 3(2): 38. doi: 10.32437/mhgcj.v4i2.86.

14. Iwasaki Y., Coyle C., Shank J. Leisure as a context for active living, recovery, health and life quality for persons with mental illness in a global context. Health Promot Int. 2010; 25(4): 483-494.

15. Krejči $M$. Strategies of mental health promotion in young athletes: Education to wellness. Acta Salus Vitae. 2015; 1(2), 37-52.

16. Yudina V., Danylova, T. Mental health problems and the ways of solving them through the eyes of Ukrainian high school students. MHGC Journal. 2019; 1(1): 87-88. doi: 10.32437/mhgcj.v1i1.38.

17. Yeung J., Zhang Z., Kim T. Volunteering and health benefits in general adults: Cumulative effects and forms. BMC Public Health. 2018; 18(1):1-8.

18. LiY., Ferraro K. Volunteering in middle and later life: Is health a benefit, barrier or both? Soc Forces. 2006; 85(1): 497-519.

19. McLeod J. Youth studies, comparative inquiry, and the local/global problematic. The Review of Education, Pedagogy, and Cultural Studies. 2009; 31(4): 270-292. doi: 10.1080/10714410903132840.

20. Pantea M. Understanding non-participation: perceived barriers in cross-border volunteering among Romanian youth. Int J Adolesc Youth. 2015; 20(3): 271-283.

21. Leccardi C. Facing uncertainty: Temporality and biographies in the new century. Young. 2005; 13(2): 123-146.

22. Thoits P., Hewitt L. Volunteer work and well-being. J Health Soc Behav, 2001; 42(2): 115-131.

23. Diamond C., Saintonge S., August P., Azrack A. The development of building wellness ${ }^{\mathrm{TW}}:$ A youth health literacy program.J J Health Commun. 2011; 16(3): 103-118.

24. Jorm A. Mental health literacy: Empowering the community to take action for better mental health. Am Psychol. 2012;67(3):231-243. doi: $10.1037 / \mathrm{a} 0025957$.

25. Whitley J., Smith J., Vaillancourt T. Promoting mental health literacy among educators: Critical in school-based prevention and intervention. Canadian Journal of School Psychology. 2013; 28(1):56-70.

26. McKinley J. Critical argument and writer identity: Social constructivism as a theoretical framework for EFL academic writing. Critical Inquiry in Language Studies. 2015; 12(3): 184-207. doi: 10.1080/15427587.2015.1060558.

27. Raskin J. Constructivism in Psychology: Personal Construct Psychology, Radical Constructivism, and Social Constructivism. American Communication Journal. 2002; 5(3): 1-26.

28. Knoll L., Leung J., Foulkes L., Blakemore S. Age-related differences in social influence on risk perception depend on the direction of influence. J Adolesc. 2017; 60: 53-63. doi: 10.1016/j. adolescence.2017.07.002

\section{ORCID and contributionship:}

Viktor V. Vus: 0000-0002-1042-5323 ${ }^{A, F}$

Elena V. Syurina: 0000-0002-6482-3909 ${ }^{A, F}$

Tanya C. Brückner: 0000-0003-3740-4925 C,D

Evangelos Fradelos: 0000-0003-0244-9760 C,E,F

Ioanna V. Papathanasiou: 0000-0002-8874-8085 C,E,F

Liudmyla M. Omelchenko: 0000-0002-9963-0306 B,C,E

Tetyana M. Vakulich: 0000-0002-5700-5035 D,E 


\section{Conflict of interest:}

The Authors declare no conflict of interest.

\section{CORRESPONDING AUTHOR}

Viktor V. Vus

National Academy of Educational Science

15 Andriivska st., 02000 Kyiv, Ukraine

tel: +380677408429

e-mail: viktorvus@ukr.net

Received: 2020-07-26

Accepted: 2021-06-01

A - Work concept and design, B - Data collection and analysis, C - Responsibility for statistical analysis,

D-Writing the article, $\mathbf{E}$-Critical review, $\mathbf{F}$ - Final approval of the article 